Brit. J. vener. Dis. (1956), 32, 27.

\title{
SOCIAL ASPECTS OF GONORRHOEA IN ENGLAND AND WALES $*$
}

\author{
BY \\ CLAUDE S. NICOL \\ St. Bartholomew's Hospital, London
}

\section{INTRODUCTION}

There has been little change in medical knowledge concerning the diagnosis and treatment of gonorrhoea in the post-war era (1946-1953). The yearly official Ministry of Health data for England and Wales indicating the total number of cases treated at a centre for the first time reached the "peak" figure of 47,343 in 1946. From then on they steadily declined year by year to 18,064 cases in 1951 , but in both 1952 and 1953 there was a slight increase over the 1951 figure. The 1953 figure of 19,263 cases was still $40 \cdot 7$ per cent. of that in 1946. The same general trend had been observed in the official figures for gonorrhoea in other European countries, and in France and Sweden there had been the same slight increase in 1953 as compared with 1951 (Table I). Thus it seemed that, in spite of high standards of diagnosis and the availability of

TABLE I

CASES OF GONORRHOEA-OFFICIAL FIGURES

\begin{tabular}{|c|c|c|c|}
\hline \multicolumn{2}{|c|}{ Country } & 1951 & 1953 \\
\hline $\begin{array}{l}\text { England } \quad \ldots \\
\text { France } \\
\text { Italy } \\
\text { Norway } \\
\text { Sweden * } \\
\text { Denmark }\end{array}$ & $\begin{array}{l}\cdots \\
\cdots \\
\cdots \\
\cdots \\
\cdots\end{array}$ & $\begin{array}{r}18,064 \\
14,664 \\
27,433 \\
1,947 \\
18 \cdot 7 \\
16 \cdot 4\end{array}$ & $\begin{array}{r}19,263 \\
16,151 \\
24,575 \\
1,648 \\
20 \cdot 8 \\
16 \cdot 3\end{array}$ \\
\hline
\end{tabular}

* per 10,000 population.

antibiotics in the treatment of gonorrhoea, the steady downward trend of reported cases had been halted, not only in Great Britain but also in some other European countries. It appeared that the time had come to concentrate on the social aspects of the disease to see if they held the clue to future control methods.

\section{Social Aspects}

There appeared to be a number of possible sociological reasons for the unsatisfactory situation which had arisen.

* Received for publication February 10, 1956.

+ Address given to the MSSVD on November 25, 1955.
(1) There was evidence that promiscuity had not decreased at the same rate as had gonorrhoea since 1946. The official figures for new cases reported by the clinics was 177,963 in 1946 and 98,671 in 1953. It was assumed that the majority would have attended as a result of running a risk of venereal disease, and that this proportion would be about the same in both years. Thus in 1953 gonorrhoea had decreased to $40 \cdot 7$ per cent. of the 1946 figure, but new cases had only decreased to 55.4 per cent. of the 1946 figure.

(2) There was evidence to suggest that year by year there persisted a " reservoir" of undiscovered gonococcal infection in the female population, because a study of the ratio of male to female cases diagnosed usually varied between $3: 1$ and $4: 1$. It had been argued that this might merely indicate that several men were infected by one woman, but a study of the male : female ratio in early infectious syphilis showed a constantly lower ratio. From the official Ministry of Health figures for 1953 the male: female ratios were: gonorrhoea $4: 1$; syphilis (1st year) 2.5:1 (to the nearest 0.5 ).

The main medical reason for undiagnosed gonorrhoea in women appeared to be the lack of symptoms of the disease. For example, it had been found that 76 ( 54 per cent.) of 140 female patients attending the Whitechapel Clinic during 1946 and 1947 as a result of contact tracing, admitted no symptoms of gonorrhoea (Nicol, 1948).

(3) There was reason to believe that the "reservoir " of undetected gonorrhoea in females might exist mainly in prostitutes and in casual sex contacts. This was supported by the fact that contact tracing methods usually brought to the clinic the girl infected by the male patient (wife or regular friend) rather than the infecting contact (prostituíe or casual acquaintance). An example of this is shown by the analysis of the contact tracing results in 190 males with gonorrhoea who attended the Special Treatment Centre at St. Bartholomew's Hospital between 1951 and 1953 (Haworth and Nicol, 1954). A contact slip could not be given in 22 per cent. of the cases because the girl was untraceable; even when a contact slip was given, a further 60 per cent. of the girls could not be traced. Of the remainder attending a clinic for examination, no evidence of gonorrhoea was found in 3 per cent., while a diagnosis of gonorrhoea was made in 15 per cent. : 12 per cent. were wives or regular girl friends, while only 3 per cent. were casual acquain- 
tances. One might conclude from this evidence that contact tracing, while being a most important and essential procedure, does not appreciably reduce the female " reservoir" of infection.

On the other hand in "Women of the Streets" (British Social Biology Council, 1955), a very valuable book containing data concerning prostitutes in London, the social worker was of the opinion that prostitutes did not play an important part in the spread of venereal diseases.

(4) Although the male was usually considered to be the "indicator" of gonococcal infection, he could also on occasions be a symptomless carrier. This has recently been emphasized in the literature (Bittiner and Horne, 1955). It was also apparent that the male was infectious and often transmitted the disease before his symptoms appeared ; for it was well recognized that a married man who had run an extramarital risk had often infected his wife before any urethral discharge appeared. This might give rise to a re-infection if, as often happened, only the husband was treated, while the wife remained infected but symptomless. Even if the wife attended as the result of contact tracing and was treated, "ping pong" re-infections might occur between husband and wife until both were treated simultaneously.

(5) There was reason to think that gonorrhoea might be imported by merchant seamen and others coming from abroad. It was presumed that most of these infections were acquired in Europe because of the short incubation period of gonorrhoea. But it was possible that infections might also come from other parts of the world, both by reason of air travel and because of the possibility of the disease being suppressed but not cured by sulphonamide drugs given in transit by sea from some distant port.

Recent papers have given some information concerning gonorrhoea in foreign ports. The World Health Organization has published figures for gonorrhoea diagnosed in merchant seamen at various ports (WHO, 1955), and an extract is shown in Table II. The Union Internationale contre le Péril Vénéréenne (UIPV) reported to its General Assembly (Naples, 1955) that gonorrhoea in 1953 had only decreased in Mediterranean ports by 38 per cent. since 1948 (see p. 52 of this issue).

TABLE II

GONORRHOEA IN SEAMEN, 1951

\begin{tabular}{|c|c|c|c|}
\hline & Town & & No. of Cases \\
\hline $\begin{array}{l}\text { Hong Kong } \\
\text { Osaka } \\
\text { Adelaide } \\
\text { Port of Spain } \\
\text { Aberdeen } \\
\text { Helsinki } \\
\text { Marseilles }\end{array}$ & $\begin{array}{cc}\ldots & \ldots \\
\ldots & \ldots \\
\ddot{\text { (Trinidad) }} \\
\ldots & \ldots \\
\ldots & \ldots \\
\ldots & \ldots\end{array}$ & $\begin{array}{l}\cdots \\
\cdots \\
\cdots \\
\cdots \\
\cdots\end{array}$ & $\begin{array}{c}67 \\
2,196 * \\
23+ \\
3,740+ \\
38 \dagger \\
145 \\
163\end{array}$ \\
\hline
\end{tabular}

* No 1950 figure. † Increase over 1950 figure.

(6) It was felt that, in addition to infection being imported from abroad, gonorrhoea might have been disseminated through the country by itinerant members of the population.
(7) It was considered that the recent increase of gonorrhoea might be influenced by the non-United Kingdom portion of the population, which had been increased by immigrants, particularly from the West Indies, since 1951.

(8) Considerable publicity had been focused on homosexuality and it was thought that this might play some part in the spread of gonococcal infection, particularly as contact tracing would be difficult.

\section{BCCG-BFVD STUDY}

In the hope of further clarifying some of these social problems the British Federation against the Venereal Diseases (BFVD) asked the British Cooperative Clinical Group (BCCG) if they would join in undertaking a survey. It was agreed to undertake an analysis of the case cards of patients with gonorrhoea who had attended the various clinics in the group during 1954. A form was prepared and approved by a committee of the BCCG and BFVD and the necessary numbers were sent to the medical officers in charge of the clinics concerned. A tribute must be paid to all those who worked so hard in completing these forms.

An analysis was obtained of 8,183 infections in 7,157 patients. In 1954 the official Ministry of Health figures reported 17,536 infections for all the clinics in England and Wales, thus the BCCGBFVD study includes 46.7 per cent. of the total infections. In the Ministry of Health figures 7,778 infections (44.3 per cent.) occurred in London (excluding Middlesex) and 9,758 infections (55.7 per cent.) in the rest of England and Wales. In the BCCG-BFVD study $3,012 \quad(36 \cdot 8$ per cent.) infections occurred in London (excluding Middlesex) and 5,171 (63.2 per cent.) in the rest of England and Wales. Thus the Study is somewhat more representative in other areas than in London. A separate paper on the BCCG-BFVD Gonorrhoea Study should be referred to on page 21 of this issue. The clinics are grouped in four areas :

(i) Ports,

(ii) Inland industrial cities,

(iii) London,

(iv) Non-industrial towns and rural areas.

The main conclusions to be drawn from the Study, taking Great Britain as a whole, may be summarized as follows :

Occupation.-Nearly 40 per cent. of the males were itinerant, but over 99 per cent. of the females were nonitinerant. Just over 20 per cent. of males were seamen; almost 20 per cent. of the women were prostitutes.

Race.-Over 90 per cent. of the females belonged to the indigenous population of the United Kingdom, but almost $\mathbf{4 0}$ per cent. of the males did not. 
Infecting Sex Contacts.-Almost 80 per cent. of the male infections but only 25 per cent. of the female infections resulted from a casual relationship. Homosexual exposures accounted for only 2.5 per cent. of the male cases.

Contraceptives.-There are rather inadequate data, but in over 90 per cent. of cases recorded no precautions were taken.

Marital Status.-Nearly 70 per cent. of the males were single, while just over 50 per cent. of the females were married.

Alcohol before Intercourse.-Data not complete ; nearly 80 per cent. of the males, but only 25 per cent. of the females, admitted taking alcoholic drinks before intercourse.

Re-infections.-Re-infections during the same year occurred in 10 per cent. of the males and in 7 per cent. of the females.

In view of the particular interest of the figures relating to merchant seamen, prostitutes, and homosexuals, it was decided to carry out a more detailed analysis of the material for :

(a) Merchant seamen in Group I (the port clinics),

(b) Prostitutes in Group III (the Iondon clinics),

(c) Homosexuals in all Groups.

(a) Merchant Seamen in Group I.-In the port clinics 44 per cent. of the seamen were not natives of the United Kingdom, while only 25 per cent. of those of all other occupations fell in the same category. Prostitutes comprised 68 per cent. of the seamen's infecting sex contacts, while those of all other occupations gave prostitutes as infecting sex contacts in only 32 per cent. of cases.

(b) Prostitutes in Group III.-In London 82 per cent. of the prostitutes were United Kingdom whites, 15 per cent. were whites of other countries, and 3 per cent. were Negroes. Of the prostitutes 24 per cent. claimed to have been married, but only 7 per cent. added that they were now separated or divorced. Only 1 per cent., however, gave the husband as the infecting sex contact; and 40 per cent. gave a friend as the infecting sex contact. In many cases this was presumably the ponce.

(c) Homosexuals in all Groups.-The percentage of homosexuals (i.e., those who admitted to homosexual contacts) by areas was as follows :

Group I (Ports), 0.4 per cent.,

Group II (Inland Industrial cities), $0 \cdot 2$ per cent., Group III (London), 5.8 per cent.,

Group IV (Non-industrial towns and rural areas), nil.

In London the 117 homosexuals all attended the West End and City clinics, and none attended the large East End clinic. This is in agreement with the conclusions of Jefferiss (1954).

\section{ReCent Studies in Other Countries}

(1) In the United States a survey (Social Hygiene News, 1955) showed that in 1954 "Gonorrhoea attack rates were up in 36 states and 23 major cities".

(2) A very instructive study was carried out in Finland in 1953 (Härö and Pätiälä, 1954), which, in many ways resembled the BCCG-BFVD Study, but included additional interesting information. A total of 5,187 cases ( 78 per cent. of all cases officially reported from clinics in 1953) were included in this survey, 2,117 (40.8 per cent.) of them from the Helsinki clinics. An analysis of the source of infections showed that 21.8 per cent. occurred in the ports, 14.7 per cent. in the industrial towns, 48 per cent. in Helsinki, $10 \cdot 1$ per cent. in rural areas, and 5.4 per cent. abroad. A further analysis of those infected abroad indicated that 46 per cent. were merchant seamen.

\section{SPREAd of Gonorrhoea}

It is felt that these studies help to confirm some of the theories previously discussed and aid in explaining the check in the steady fall of the gonorrhoea figures between 1946 and 1951. The "reservoir" of undiagnosed female gonorrhoea consists mainly of prostitutes and of " amateurs" who have many casual male acquaintances. This " reservoir" is kept " topped up" by the importation of fresh infection from abroad, chiefly by merchant seamen, which is transmitted in the first place mainly to prostitutes. Infection is carried round the country from one area to another by those of itinerant occupation. Most of the females who have been treated at clinics for gonorrhoea are wives or regular girl friends who have been infected by male patients. This concept of the spread of gonorrhoea is illustrated in Fig. 1 (overleaf).

\section{Organizations Which TAKe PaRT IN THE CONTROL of Venereal Diseases}

\section{National}

(i) British Federation against the Venereal Diseases (BFVD) is an unofficial, i.e., non-governmental, organization with representatives from fifteen member organizations, three medical and twelve social). It deals mainly with the social aspects of these diseases (Nicol, 1954).

(ii) Medical Society for the Study of Venereal Diseases (MSSVD), with over 250 members, deals mainly with the medical problems of venereal disease. It has been instrumental in forming the British Cooperative Clinical Group (BCCG), which gathers statistical data of both medical and social importance. The MSSVD is a member of the BFVD with three representatives on its Executive Committee. 


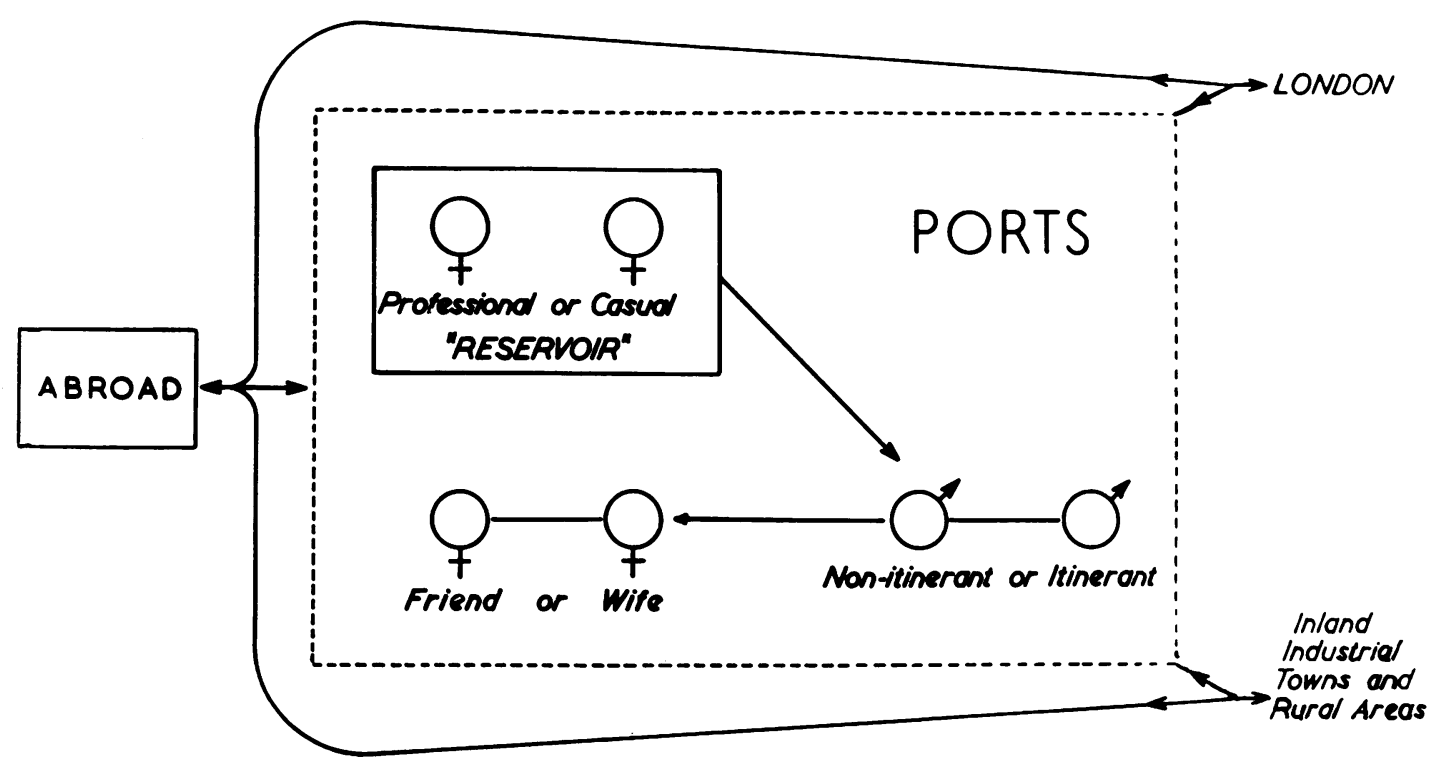

Fig. 1.-Spread of Gonorrhoea.

(iii) British Medical Association (BMA) has an elected Consultants Committee Group in Venereology. The BMA is a member of the BFVD with a representative on its Executive Committee. The BMA publishes the British Journal of Venereal Diseases with the aid of an editorial committee of the MSSVD.

(iv) Central Council for Health Education (CCHE) receives a grant from local health authorities and one of its responsibilities is the education and instruction of the public concerning venereal diseases. It is a member of the BFVD with a representative on its Executive Committee.

(v) Ministry of Health appoints an Adviser and Assistant Adviser in venereal disease. They deal with matters of general policy, official propaganda, the publication of official forms, and statistical returns for clinics. At present the Adviser is on the Executive Committee of the BFVD.

(vi) Medical Officers of Health (MOsH) remain responsible for the preventive medicine aspects of venereal diseases in their respective areas. The Chief Medical Officer of the London County Council is Chairman of the Executive Committee of the BFVD.

(vii) United Kingdom Committee of the World Health Organization (WHO) deals with world health matters as they affect this country and is in close touch with WHO headquarters in Geneva.
The BFVD is a foundation member and at present has a representative on its Executive Committee.

(viii) Twelve non-medical organizations, concerned with various aspects of the venereal disease problem, which are members of the BFVD with a representative on the Executive Committee :

Apostleship of the Sea.

Association for Moral and Social Hygiene.

British Social Biology Council.

Church of England Moral Welfare Council.

Institute of Almoners.

Invalid Children's Aid Association.

Mission to Seamen.

National Association for Maternal and Child Welfare.

National Association of Probation Officers.

National Council of Women of Great Britain.

Royal College of Nursing.

Scottish Council for Health Education.

(ix) Medical Services of the Armed Forces.-The Advisers in Venereology of the Services are invited as observers to the Annual General Meetings of the BFVD; as individuals they may be members of the MSSVD.

\section{International}

(i) "Union Internationale Contre le Péril Vénéréenne et les Treponematoses" (UIPV) is an international governmental organization of which the BFVD is a member. It holds General Assemblies in different countries every 2 years and deals 
INTERNATIONAL

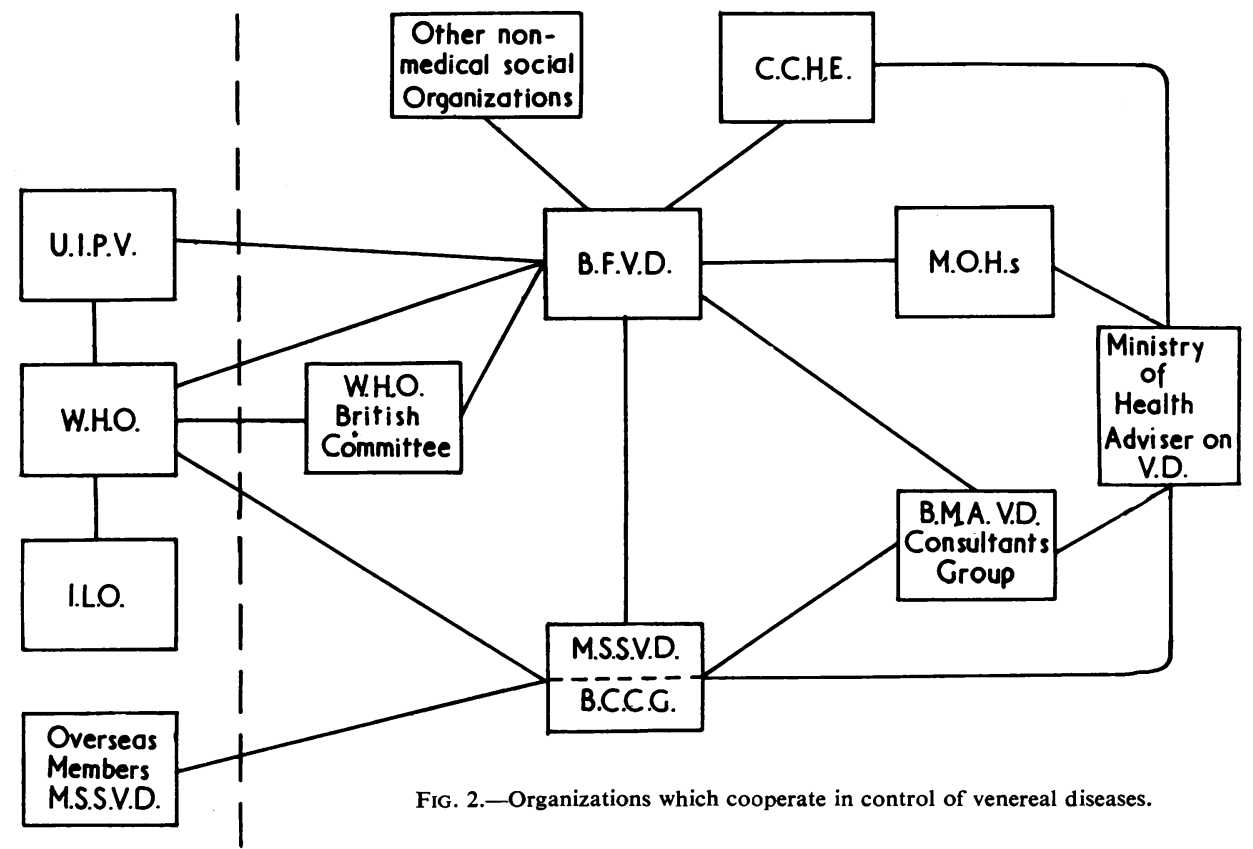

mainly with social problems. The UIPV holds consultative status with WHO (at Geneva).

(ii) World Health Organization (WHO) has a Venereal Diseases and Treponematosis section with headquarters and a chief officer in Geneva. They undertake the planning, organization, and, to some extent, the staffing of venereal disease control programmes at the invitation of governments, mainly in under-developed countries. They are able and willing, however, to help any national survey in various ways, for instance by supplying statistical help.

(iii) International Labour Organization (ILO) with headquarters in Geneva, among other matters, deals with the welfare of seafarers. There is a joint ILO/WHO Committee on which the British Shipping Federation is represented.

(iv) Overseas members of the MSSVD representative of a number of Commonwealth and foreign nations and of WHO visit this country, giving lectures at the MSSVD They also contribute papers to the British Journal of Venereal Diseases on both medical and social subjects.

A representation of the relationship between these various organizations is seen in Fig. 2.

\section{National}

Policy-Present and Future

(i) Statistics.-At the suggestion of the BFVD the official quarterly figures for gonorrhoea (and other venereal diseases) now appear in the Vital Statistics column of the British Medical Journal. A yearly report is published by the Chief Medical Officer of the Ministry of Health. (See this issue, page 47). These figures do not, however, give a true picture of the prevalence of gonorrhoea in England and Wales because there are no reports on :

(a) Cases occurring in the British Armed Forces,

(b) Cases occurring in the United States Armed Forces in the United Kingdom,

(c) Cases treated by consultants in private practice,

(d) Cases treated by general practitioners privately or under the National Health Service.

As the treatment of gonorrhoea appears to be such a simple matter, it is likely that the total from all these categories may represent a very large number of cases. It would be of great interest to obtain some estimate of this unknown quantity. The Ministry of Health could probably obtain in confidence an estimate of the number of men treated in the British and U.S. Armed Forces in the United Kingdom, and it might be possible for the BMA or the College of General Practitioners to send a confidential questionnaire to consultant venereologists and general practitioners in a chosen area, asking only for the number of patients treated, without any personal details. From these figures an estimate could be made for the whole country.

(ii) Sex Education.-The prevention of promiscuity is obviously not only a venereal disease 
problem but a moral issue which is also closely linked with the evils of juvenile delinquency, illegitimacy, and crime. The child will need a happy home with the minimum of parental discord ; there must be early and intelligent sex education which will be followed up at schools and youth clubs ; the Armed Services must play their part by giving the young National Serviceman lectures on venereal disease; at a later age marriage guidance organizations should give help and advice. For these purposes pamphlets, newspaper articles, radio and television, and films and film strips could play an important part. Some youth organizations at present tend to turn a blind eye to the problem of venereal disease and have rejected an offer by the BFVD to cooperate with the CCHE in making film strips and training group leaders to introduce discussions on this subject. Further efforts must be made to convince them that knowledge is preferable to ignorance.

A further analysis of the 1954 BCCG-BFVD Study on Gonorrhoea showed that 3.6 per cent. of the males and 14.3 per cent. of the females werc under 20 years of age. Allowance must be made for the fact that many " teenage " males were doing National Service in the Armed Forces; it is interesting that in Group 1 (the ports) the male " teenage" figure was increased to 5.0 per cent., the majority being merchant seamen (presumably doing National Service in the Merchant Navy). It remains a most disturbing fact that one in every seven females attending the clinics with gonorrhoea in 1954 was a "teenager".

The BFVD is undertaking a Pilot Survey on the Public Reactions to VD Health Education. A questionnaire has been drawn up and will be filled in by social workers for patients attending a clinic irrespective of whether they have a venereal disease or not. This survey has been begun at a clinic in London, and it is hoped that when completed it may give some guidance to the CCHE for their future policy in health education.

(iii) Prophylaxis.-It is most important to realize that the need for prophylaxis indicates that sex education has failed. Even so, there seems to be supporting evidence in the BCCG-BFVD Study in favour of advocating the old and established mechanical methods. On the other hand the more recently advocated antibiotic prophylactics seem much more dangerous as they may suppress other venereal diseases and, in the long run (especially if administered orally), may even produce resistant strains of gonococci. Their use may be justified in certain circumstances in the Armed Forces, but it is difficult to believe that they will do anything but harm in a civilian population. Nor would prophylactic treatment of the female contacts with antibiotics advocated by some venereologists (" treatment before diagnosis") appear to help in the control of gonorrhoea; undoubtedly some women who were, in fact, not infected would receive treatment with the attached stigma of the disease. For example, in the study already referred to (Haworth and Nicol, 1954), only 18 per cent. of the female contacts attended a clinic and would have been available for prophylaxis. In fact, 15 per cent. were found to have gonorrhoea and were treated, but the remaining 3 per cent. were finally found to have no evidence of gonorrhoea and were not treated. They had not been infected by the male concerned.

(iv) Contact Tracing.-Although the scope of contact tracing is somewhat limited, as has been already illustrated, it is none the less a most important procedure.

The National Contact Slips which were initiated by the BFVD and approved by the MSSVD and Ministry of Health (Nicol, 1954) should, if possible, be used in all clinics. In order that they should be put to the best use, it is considered that it is essential for a clinic to have a social worker. A memorandum sent out to clinics by the VD Consultants Group of the BMA elicited the fact that a number of medical officers in charge of clinics needed, but were unable to obtain, a social worker. After consultation with the Society of Medical Officers of Health, a joint deputation discussed the problem with a representative of the Ministry of Health : the outcome of this is still awaited.

(v) Social Studies.-It is felt that, as a result of obtaining much useful data from the 1954 BCCGBFVD Retrospective Gonorrhoea Survey, a further premeditated survey should be undertaken. It is possible that statistical aid and help with punchcards might be obtained. An agreed questionnaire would have to be drawn up, and applied to all new patients with gonorrhoea in the clinics concerned from an agreed date. The three most important problems on which more social data are needed appear to be :

(1) Merchant Seamen and other itinerants,

(2) Prostitutes and casual (amateur) girls, i.e., the "reservoir",

(3) The non-United Kingdom group in this country.

(vi) Anti-VD Propaganda.-After 1946, as the figures for gonorrhoea (and other venereal disease) fell year by year, somewhat naturally anti-VD propaganda to the general public diminished proportionately, so that by 1951 there was virtually 
none. Now that it is realized by venereologists that a greater effort is needed, it is not so easy to get the machinery working again. The public feel that gonorrhoea is no longer a menace and neither the national press nor the $\mathrm{BBC}$ is very ready to disillusion them. Various approaches by the BFVD to the BBC have had no results. Television (including ITA) is a new and untried field. The present studies would suggest that future propaganda will now have to concentrate on special groups of the population in which the incidence of the disease is high.

(a) It will have to be accepted that the women composing the female " reservoir" of undiagnosed gonorrhoea are and will remain promiscuous. They should be encouraged to attend the clinics for a "check up" on a disease which they "may not know they have" and once there should be kept under observation and encouraged to re-attend for so long as they continue to have intercourse with "pick-ups" or casual acquaintances.

(b) The non-United Kingdom Group includes many merchant seamen, and very simple forms of propaganda will have to be used, possibly posters of the graphic or "strip cartoon" type, as many individuals in this group will be of low intelligence. These would be needed most in the ports and large cities. The language problem would also have to be considered. These matters should be further considered by the BFVD and discussed with the Adviser to the Ministry of Health and with the CCHE.

\section{International}

(i) Statistics.-It is hoped that in future the European Office of the UIPV will circulate the member countries in its region, informing them of the annual statistics of venereal diseases in each country. It is also a function of the UIPV to bring to the notice of governments the continuing menace of the venereal diseases, in spite of the great progress made since 1946. After the General Assembly (Naples, 1955) such a resolution was tabled. In Great Britain an unofficial report of the General Assembly was submitted to the Ministry of Health (through its Adviser in Venereal Diseases) and the official resolutions appear in this issue of the British Journal of Venereal Diseases (p. 52).

(ii) Contact Tracing.-The UIPV has discussed methods of notifying contacts in other countries. In Great Britain it is not permissible to send the actual names of contacts, but it might be possible, either officially via the Ministry of Health, or unofficially via the BFVD, to notify the dates and places of origin of cases of gonorrhoea (and other venereal infections). In this way the health authorities of any country would have some idea of the amount of gonorrhoea being " exported " and could take the necessary steps. This scheme would naturally depend on the cooperation of medical officers in charge of clinics, who would have to submit the necessary returns at set intervals.

(iii) Social Studies.-Exchange of information concerning social studies of a similar nature should take place between different countries. This can be done best through the agency of an international organization. At the General Assembly of the UIPV, the author heard by chance of the Finnish Study in Gonorrhoea and also of the 1954 study in the United States, details of which were published in a very excellent small pamphlet (Social Hygiene News, 1955). The UIPV should take a more active part in disseminating this type of information in the future.

(iv) Anti-VD Propaganda.-There was an excellent exhibition of this type of propaganda at the UIPV Assembly (Naples, 1955) and, although many of the methods would not be applicable in Great Britain, there were some interesting new ideas. It is hoped that the BFVD can collect some of this international propaganda material at a future date, so that those who may be interested can study it. Incidentally, it was pleasing to note that the British Journal of Venereal Diseases was on show at Naples together with other national publications. This is now the main journal on venereal diseases in the English language, since the American Journal of Syphilis, Gonorrhoea and Venereal Diseases widened its scope and became the Journal of Chronic Diseases.

My thanks are due to Mr. A. J. King, FRCS, Chairman of the BCCG and particularly to Dr. R. R. Willcox, Secretary of the BCCG, who has worked so hard on the forms and statistics of the BFVD-BCCG Study. I should also like to thank Dr. G. L. M. McElligott, Adviser in VD to the Ministry of Health, for his help in giving information concerning the official 1954 figures for gonorrhoea in England and Wales.

\section{REFERENCES}

Bittiner, J. B., and Horne, G. O. (1955). British Journal of Venereal Diseases, 31, 155.

British Social Biology Council (1955). "Women of the Streets : a Sociological Study of the Common Prostitute”, p. 93. Ed. C. H. Rolph. Secker and Warburg, London.

Extract from the Annual Report of the Chief Medical Officer, 1953 (1955). British Journal of Venereal Diseases, 31, 44.

Härö, A. S., and Pätiälä, R. (1954). Ann. Med. exp. Biol. Fenn., 32, Suppl. 10.

Haworth, M. C., and Nicol, C. S. (1954). British Journal of Venereal Diseases, 30, 36.

Jefferiss, F. J. G. (1954). Brit. med. J., 2, 1200.

Nicol, C. S. (1948). British Journal of Venereal Diseases, 24, 26. (1954). Ibid., 30, 170.

Social Hygiene News (1955). Vol. 30, No. 3.

World Health Organization (1955). Technical Report Series No. 92 , Geneva. 